\title{
Genetic and nutritional diversity of Bacillus subtilis isolates demonstrating different aspects related to plant growth promotion
}

\author{
Bianca de Melo Silveira dos Santos ${ }^{1}$, Maura Santos dos Reis de Andrade Silva ${ }^{1}$, Davy William Hidalgo \\ Chávez ${ }^{2}$, Everlon Cid Rigobelo ${ }^{1}$
}

\author{
${ }^{1}$ Graduate Program in Agricultural Microbiology, Faculty of Agrarian and Veterinary Sciences, State University of \\ São Paulo (UNESP), Jaboticabal, Brazil \\ ${ }^{2}$ Graduate Program in Food Science and Technology, Federal Rural University of Rio de Janeiro (PPGCTA-UFRRJ), \\ Seropédica, Brazil
}

\section{Abstract}

Currently, agricultural practices have been undergoing intense transformations, imposing major challenges such as maintaining productivity with lower production costs and environmental impacts. One of the alternatives to meet these requirements is the use of plant growth promoting bacteria, including Bacillus subtilis. However, different isolates may express different aspects and levels of plant growth promotion. The present study aimed to verify the genetic and nutritional diversity of eight $B$. subtilis isolates, demonstrating different aspects and levels of plant growth promotion. Eight $B$. subtilis isolates were analyzed as to their nutritional diversity by BiologEcoPlate ${ }^{\mathrm{TM}}$ kit, genetic diversity by Box-PCR, and a trial in greenhouse conditions. The experimental design in greenhouse trial was completely randomized with 9 treatments and five replicates, resulting in 45 pots. Treatments were eight Bacillus subtilis strains, and a control treatment using plants without bacterial inoculation. Isolates 290 and 287 are genetically similar, while isolates 248 and 263 also showed similarity. Genetic and substrate consumption (carbon) analyses showed differences and similarities among isolates, allowing the distribution of isolates into different groups. It was observed that the isolate with the highest ability to promote plant growth was the only isolate that consumed glycyl-L- glutamic acid. These results open the way for further investigations in an attempt to clarify what are the conditions and / or characteristics required by isolates for the plant growth promotion to be more effective.

Keywords: Bacillus subtilis; plant growth-promoting; maize; soybean.

Abbreviations: Colony forming unit - CFU; PCA - principal component analyzes.

\section{Introduction}

The practice of conventional agriculture often uses large amounts of synthetic fertilizers and insecticides that promote intense adverse effects on humans, animals and environment. To mitigate these effects, researchers around the world are engaged in finding alternatives aimed at the production of agricultural crops that are less dependent on the use of these inputs. One alternative is the use of rhizospheric bacteria as vital components of soil fertility and plant growth promotion through their direct and indirect processes in plant rhizosphere (Aloo et al., 2019).

Plant rhizospheres are special environments with complex root-soil-microorganism interactions (Jha et al., 2013). These complex interactions are strongly driven by root exudation that serves to attract beneficial bacteria from soil to roots (Bhattacharyya et al., 2016; Zhang et al., 2017) and as a result, plant rhizospheres support large amount of bacteria that are commonly referred to as plant growth promoting rhizobacteria (PGPR) or beneficial rhizobacteria (Raza et al., 2016). Evidence suggests that rhizobacteria are able to directly or indirectly improve plant growth in a number of ways (Patel and Minocheherhomji, 2018), including biological nitrogen fixation, nutrient solubilization, phytohormonium biosynthesis, antibiotics, hydrolytic enzymes and resistance induction for their pathogens (Gupta et al., 2015).

Rhizobacteria that improve nutrient availability and nitrogen fixation, phosphorus solubilization, or iron acquisition are commonly referred to as biofertilizers (Kuan et al., 2016). There is evidence showing that some bacteria are very useful in mobilizing and solubilizing soil nutrients compared to non-rhizospheric bacteria (Haya et al., 2010) and are therefore strongly related to soil fertility (Glick, 2012). Rhizobacteria that contribute to the suppression of plant pathogens by antagonism and competition are called biocontrol or bioinsecticide agents (Chowdhury et al., 2013), while others that contribute to the degradation of organic pollutants and reduction of metal toxicity in contaminated soils are called bioremediators (Goswami et al., 2016).

Bacillus subtilis are rhizobacteria present in the rhizosphere and represent $95 \%$ of Gram positive bacterial populations, being able to improve plant growth through the production of various antibacterial and antifungal substances (Goswami et al., 2016), and due to their ability to produce siderophores (Compant et al., 2005), lytic enzymes (Nelson, 2004), produce spores and are easily formulated (Aloo et al., 2019). 
However, the plant growth promoting characteristics of the above mentioned plants are dependent isolates and have large variation from isolate to isolate among $B$. subtilis. The present study aimed to identify genetic and nutritional differences that could explain the different effects of plant growth promotion demonstrated by eight $B$. subtilis isolates.

\section{Results}

From the classification of isolates belonging to the same genus and species, the BOX-PCR analysis was performed, which consists of the use of complementary primers to the highly conserved and repetitive DNA sequence, which is abundantly found in most bacterial genomes. Through this technique, it was possible to identify the profile of amplified bands (Fig 1), which characterized the gene difference among isolates, and the presence of clusters according to their similarities.

The formation of two clusters was observed, one represented by isolate 290 and 287, and the other by isolates 248 and 263, which showed great similarities in the pattern of amplified genes. Isolates 291, 320 and 309 exhibited a gene profile different from the others, which allows us inferring that they are distinct from other isolates. For isolate 274, there was no amplification for the BOX region, suggesting that it has a gene pattern completely different from the others.

\section{Metabolic profile of isolates}

In order to evaluate the metabolic profile of isolates to verify the consumption of the most varied carbon sources, isolates were submitted to Ecoplate analysis. Each plate contains 31 carbon sources divided into 10 carbohydrate sources, 9 carboxylic acid sources, 6 amino acid sources, 4 polymer sources, and 2 amine sources.

The results were expressed in a heatmap (Fig 2), in which it is possible to observe formation of two hierarchical groups, one of them composed of groups of isolates and the other of substrate consumption.

In the groups of isolates, the formation of two clusters can be identified; one formed by isolates 274 and 291, and the other by isolates 287, 263, 290, 320, 309 and 248. It was observed that some isolates have similar consumption; thus, statistical tools were used to analyze the consumption of different substrates and to verify that there are correlations between them (Fig 4). For the groups of substrates, two main clusters were obtained, visually presented by the heatmap color expressiveness (red, higher substrate consumption; black, intermediate consumption, and yellow, lower consumption). Substrates that had the highest consumption were the following carboxylic acids: Dglycosaminic acid, D-galactonic- $y$-lactone acid, Dgalacturonic acid, y-hydroxybutyric acid; carbohydrates: pyruvic acid methyl ester, $\beta$-methyl-D-glycoside; amino acids: L-threonine and L-arginine; and polymer: Glycogen. Substrates with the lowest consumption were carboxylic acids: itaconic acid, 4-hydroxybenzoic acid, D-malic acid, 2hydroxybenzoic acid, $\alpha$-ketobutyric acid; carbohydrates: glucose-1-phosphate, D,L- $\alpha$-glycerol phosphate, i-erythritol, D-cellobiose, D-xylose, $\alpha$-D-lactose, D-mannitol, N-acetyl-Dglucosamine; amino acids: L-phenylalanine, L-serine, glycylL-glutamic acid, L-asparagine; polymers: tween 80, tween 40, $\alpha$-cyclodextrin; and amines: phenylethylamine, putrescine. It was observed that isolate 291 is related to higher consumption of D-cellobiose, D-xylose and $\alpha$-Dlactose. Isolate 274 was the only one that consumed the carbon source from itaconic acid, glucose-1-phosphate, Dmalic acid, and D, L- $\alpha$-glycerol phosphate. Isolate 263 was the only one that consumed the tween 40 source, isolate 290 , the only one that consumed glycyl-L-glutamic acid and isolate 248 the only one that consumed L-phenylalanine. Isolate 287 is different from the others according to its carbon source consumption, using only 9 of the 31 available sources (Fig 2).

\section{Plant growth promotion}

In order to evaluate plant growth promotion using isolates classified as $B$. subtilis, a greenhouse experiment was conducted using maize crop. The experiment lasted sixty days and four inoculations were performed for each strain. In this experiment, soil moisture, respiratory activity, biomass carbon, dehydrogenase production and root and shoot dry matter were evaluated (Fig 3).

From results of Fig 3, the behavior of isolates in interaction with soil microbial activity was observed. For soil moisture, isolates that stood out were 291, 263 and 287 with values above $30 \%$, while isolate 309 had the lowest value, $22.79 \%$, which was lower than control.

For respiratory activity, isolates that most produced $\mathrm{CO}_{2}$ were 263, 290 and 320, and isolates with the lowest $\mathrm{CO}_{2}$ production was 287, followed by control.

For soil C production, isolate 248 stands out, producing $191.65 \mu \mathrm{g} \mathrm{g}^{-1}$ of $\mathrm{C}$, followed by control and isolate 287 , and isolates with the lowest C production were 291 and 290. For dehydrogenase production, isolates 263, 291, and 320 stood out, and the others had similar values, and control was the one with the lowest production.

In plant growth promotion, according to shoot and root dry matter data, the most prominent isolate was 290 with the highest values. In contrast, control and isolates 263 and 287 showed the lowest results in shoot dry matter; in root dry matter, isolate 263, 248 and also control presented the lowest results.

\section{Metabolic profile and plant growth promotion correlation}

In order to evaluate the correlation between consumption of the most diverse carbon sources (Fig 2) and plant growth promotion (Fig 3), their respective results were crossed, and strong interaction was observed according to the Pearson's correlation coefficients proposed by Teles et al. (2018), being expressed in Fig 4.

It was observed that all correlation values are above 0.7 either positive or negative, representing strong ( 0.7 to 0.9 or -0.7 to -0.9 ) and very strong (0 9 to 1.0 or -0.9 to -1.0 ) correlations. Correlation means the degree of association of two response variables. When correlation is negative, one variable increases and the other decreases; when positive, both variables increase. It is also observed that there are no values for all variables, i.e., $p>0.05$ indicates that is has no statistical significance.

\section{Principal component analysis (PCA)}

Fig 5 corresponds to the biplot formed by the first two principal components (CP1 and CP2) and ensuring that the sum of the variability retained in these components is $71.5 \%$ of the original variability, of which CP1 and CP2 have $51.4 \%$ 
and $20.1 \%$, respectively. The projection in a two-dimensional plot, the biplot, seeks to specify the behavior of variables and to contemplate associations among isolates, as well as to point out which isolates are closely related to substrate consumption and plant growth promotion. Isolates that are in the direction of variables indicate higher consumption of a given carbon source, and in the opposite direction, lower consumption. Isolates that are located at the extremities of the plane exhibit specific characteristics, being distinct from the others, and isolates that are closer, are more similar.

The purpose of using this tool is to show the most relevant information from a data table to facilitate data presentation as new common variables called principal components (Abdi $\&$ Williams, 2010). The data set was arranged in a nine-row matrix corresponding to samples and thirty-seven columns corresponding to the thirty-one carbon source of the BiologEcoPlate ${ }^{\mathrm{TM}}$, and to the six parameters analyzed regarding plant growth promotion: soil moisture, respiratory activity, biomass carbon, dehydrogenase production, root and shoot dry matter.

In Fig 5, it was possible to identify strong correlation of isolate 290 with variables glycyl - L-glutamic acid, L-arginine and shoot dry matter. Isolate 287 showed strong correlation with glycogen and isolate 274 strong correlation with D mannitol, I-irritritol, and D, L- $\alpha$-glycerol phosphate. It was observed that some isolates, 248 and 309, 320 and 291 are close, suggesting similarity in the consumption of carbon sources and plant growth promotion. It is possible to consider that isolates are divided into 4 groups, isolate 274 alone, a second group formed by isolates 320 and 291, the third formed by isolate 287, and the fourth group formed by isolates 290, 263, 248 and 309 (Fig 6).

\section{Discussion}

Differences in the growth promotion of plants that received the eight $B$. subtilis isolates in greenhouse is a result of genetic differences, since isolates did not have $100 \%$ similarity, in addition to interactions between plant and rhizospheric microbiota that promote different gene expressions.

Previous studies with the same $B$. subtillis isolates have shown significant differences in shoot and root dry matter for both maize and cotton (Lobo, 2018; Diaz 2018). Dry matter is usually a consequence of the synthesis of phytohormones produced by microorganisms. They increase the contact surface of the plant root, allowing greater interaction between microorganisms and plant, in which the microorganism is favored by obtaining nutrients and carbon from plant roots by rhizodeposition and the plant is favored by increased soil exploration efficiency, thereby increasing its nutrient and water absorption capacity (Wang et al., 2009; White et al., 2014).

In respiratory activity, isolates 263, 290 and 320 presented higher significant values. $\mathrm{CO}_{2}$ emission in the soil occurs through microbial respiration, root respiration, decomposition of plant residues, and oxidation of soil organic matter (Lal, 2009). However, soil moisture and temperature directly affect its emission over time (Paustian et al., 2000; Almaraz et al., 2009; Chavez et al., 2009; Almagro et al., 2009; Panosso et al., 2009). For $\mathrm{CO}_{2}$ production, there is an optimal humidity that promotes respiration. Excessive soil microbial respiration is limited by reduced oxygen propagation essential for aerobic cell respiration (Lal, 2009). These results suggest that isolates 263, 290 and 320 have great ability for nutrient cycling and soil nutrient mineralization.

For the dehydrogenase activity, isolates that presented significant values were 263, 291 and 320. Dehydrogenase is an enzyme that has influence on microbial activities because it affects the total oxidative activity of the soil microbiota, which is an oxidoreductase enzyme (Gu et al., 2009). Its process occurs intracellularly in all living microbial cells, not accumulating extracellularly in the soil (Salazar et al., 2011). Isolate 290 stood out for promoting higher plant growth (Fig $3-E, F)$ and higher amount of root and shoot dry matter. Lobo, (2018) and Diaz (2018) also found that B. subtilis 290 significantly increased plant growth promotion as well as nitrogen concentration in shoots and roots. Plant growth promoting bacteria have the ability to promote biological nitrogen fixation, which could be reported by Mehmood et al., (2018), who emphasized that $B$. subtilis bacteria were able to increase around $20-30 \%$ in nitrogen concentrations in grassy plants, among them, maize.

Given the results, isolate 290 was the only one capable of consuming glycyl-L-glutamic acid (Fig 4), which was positively correlated with shoot dry matter increment with p> 0.84 (Fig 5). Regarding the results of principal components, this correlation is strongly evidenced, suggesting that this isolate has an effect on glutamate, and the shoot and root dry matter increment is also strongly related by the analysis. Through studies of the metabolic diversity of microorganisms, Sala et al. (2006) reported that ecosystems can adapt to constant nutrient changes and adapt to various carbon sources, which can be used for their growth, as some components may be present in their cell structure. Thus, these microorganisms express great ability to develop due to the various metabolic pathways.

An important amino acid for plant growth, development and metabolism is glutamic acid or glutamate. Its function is directly linked to the plant defense mechanism due to its participation in the production of glutathione that acts against plant stress, acting in the enzymatic and nonenzymatic defense system by neutralizing the behavior of oxygen reactive species through their ability to donate electrons. In addition to the defense mechanism, glutamic acid is a key amino acid in the functioning of meristems, fruiting, growth, protein and sugar synthesis in plants (Gill., 2010).

Glutamate is synthesized through the absorption of nitrogen by plants, which although a basic amino acid, plays an important role through its transformation into other amino acids essential for plant metabolism, originating arginine, asparagine, proline, aspartate and glutamine through aminotransferase activity (Buchanan et al., 2000; Taiz; et al., 2013). Plant-absorbed $N$ (available in various forms $\mathrm{NH}_{4}{ }^{+}$and $\mathrm{NO}_{3}{ }^{-}$) can be altered as a function of its development cycle (Bredemeier et al., 2000; Williams \& Miller, 2001). $\mathrm{NO}_{3}{ }^{-}$can be assimilated into shoot or roots; however, this amino acid needs to be reduced to $\mathrm{NH}_{4}{ }^{+}$( $\mathrm{Li}$ et al., 2013). Once reduced, $\mathrm{NH}_{4}{ }^{+}$is assimilated by glutamine synthetase (GS) enzymes, incorporating $\mathrm{NH}_{4}{ }^{+}$into glutamate, thereby obtaining glutamine through the reaction requiring $A T P$, which then glutamate synthase or glutamine-2-oxoglutarate aminotransferase (GOGAT) provides a glutamine $\mathrm{N}$ amide to 2-oxoglutarate to obtain two glutamate molecules (Lea \& Miflin, 2011). An alternative route for glutamate formation may still occur, where 


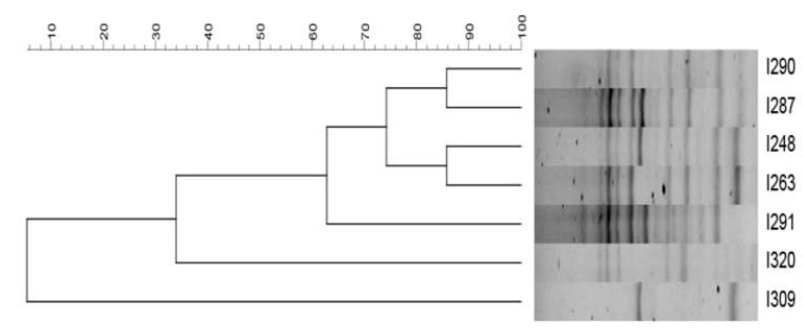

Fig 1 . Electrophoretic profile in $0.8 \%$ BOX-PCR agarose gel of isolates showing the genetic similarities between the isolates 1-Isolate 290; 2 - Isolate 287. 3 - Isolate 248; 4 - Isolate 263; 5 - Isolate 291; 6 - Isolate 320; 7 - Isolate 309. Six groups were grouped, and the higher genetic similarities were between isolates 290 and $287 ; 248$ and 263.

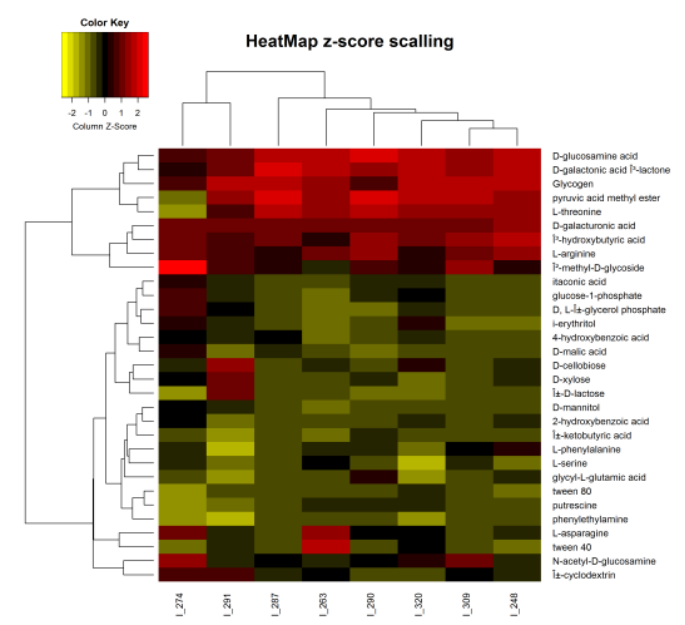

Fig 2 - Heatmap and hierarchical grouping of isolates and 31 carbon sources by BiologEcoplate using all incubation times. The highest similarities in consumption of carbon sources were between isolates 274 and 291; 209 and 248. The color key shows the intensity of the consumption of carbon sources.

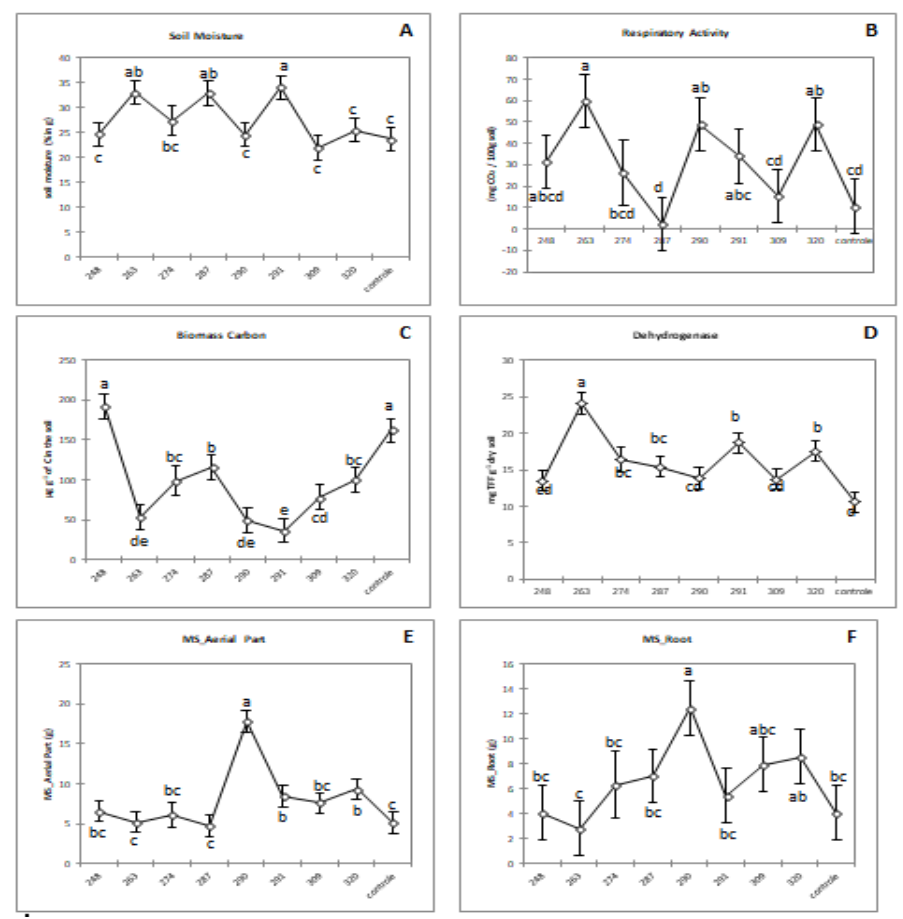

Fig 3 Soil Moisture (A), Respiratory Activity (B), Biomass Carbon (C), Dehydrogenase (D), Shoot Dry Matter (E) and Root Dry Matter (F) of maize plants inoculated with eight isolates of endophytic bacteria of the genus Bacillus subtilis and control without inoculation at day 60. Means with different letters indicate significant difference of $5 \%$ according to the Tukey test. 


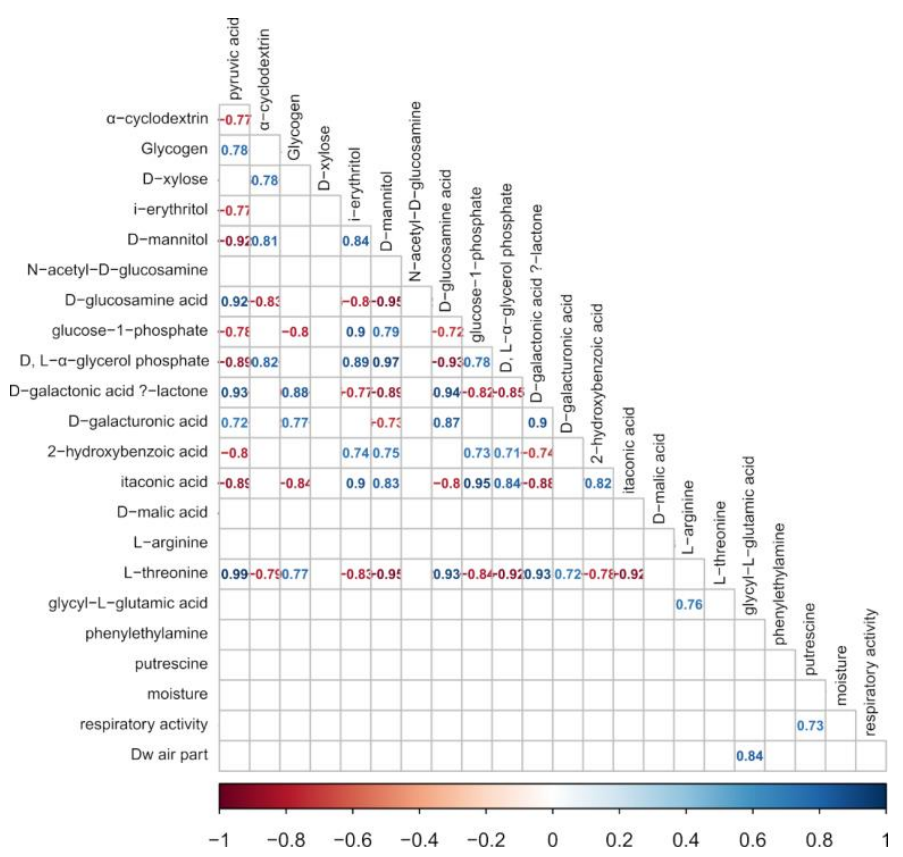

Fig 4. Pearson correlation coefficients of the consumption of carbon sources BiologEcoPlate ${ }^{\mathrm{TM}}$, and plant growth promotion by Bacillus subtilis isolates.

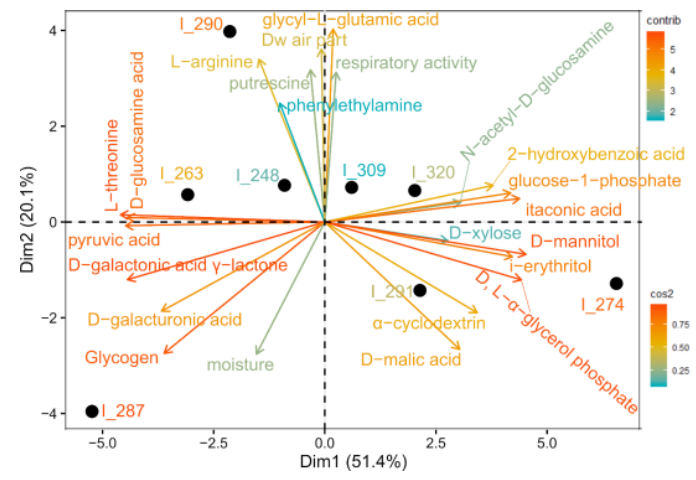

Fig 5. Spatial biplot projection of principal components (PCA), referring to the consumption of carbon sources and plant growth promotion. Each quadrant, the bacterial isolate, and its relationship between carbon sources and soil activities are shown. Arrows in the same quadrant and the same direction indicate a positive relationship.

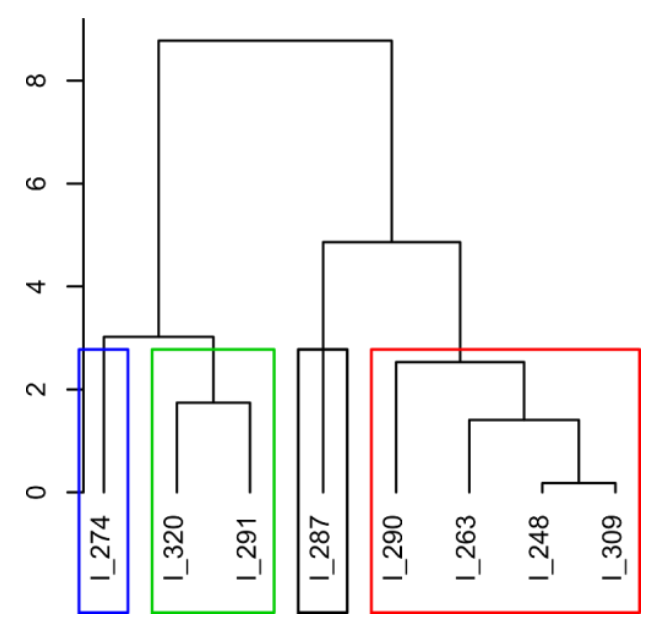

Fig 6 Principal components analyzes (PCA), referring to the consumption of carbon sources and plant growth promotion. 
glutamate dehydrogenase (GDH) performs the reversible catalysis of 2-oxoglutarate amination (Terce-Laforgue et al., 2013).

These data suggest a direct symbiosis with the plant, as this isolate - 290 - possibly acted as the largest nitrogen fixator, as shown by Lobo (2018), which is an essential element in the glutamate percussion to plants. It is believed that plant uses $\mathrm{N}$ from biological fixation through this isolate, following its metabolic pathway in glutamate synthesis, possibly providing microorganism with this carbon source, in which both are benefited, promoting greater plant growth and development, and greater isolate stability.

The aim of the present study was to understand why $B$. subtilis isolates with plant growth promotion abilities act on different parameters related to soil microbial activity and plant growth promotion. Genetic and substrate consumption (carbon) analyses showed differences and similarities among isolates, allowing the distribution of isolates into different groups.

\section{Materials and Methods}

\section{Experimental design (Greenhouse)}

The experiment was conducted in greenhouse belonging to the Laboratory of Agricultural Microbiology - Faculty of Agrarian and Veterinary Sciences / UNESP, Jaboticabal campus, SP.

The experimental design was completely randomized with 9 treatments and five replicates, resulting in 45 pots. Treatments were eight Bacillus subtilis strains, and a control treatment using plants without bacterial inoculation.

Five maize seeds obtained from the commercial 2B587PW hybrid (Dow Agro Sciences) were sown in 5-liter pots containing previously sieved soil. Soil fertilization was performed according to soil chemical analysis and recommendations for the crop, following indications of Raij and Cantarella (1997) for expected yield of 8 to 10 t.ha $^{-1}$, applying $100 \mathrm{~kg} \mathrm{ha}^{-1}$ of nitrogen in the form of conventional urea, $60 \mathrm{~kg} \mathrm{ha}^{-1}$ of $\mathrm{P}_{2} \mathrm{O}_{5}$ (triple superphosphate) and $50 \mathrm{~kg}$ $\mathrm{ha}^{-1}$ of $\mathrm{K}_{2} \mathrm{O}$ (potassium chloride), with their quantities properly calculated for pot volume. One week after plant emergence, pruning was performed, leaving one plant per pot. The experiment was conducted for a period of 60 days, and inoculations were performed every 8 days with volume of $10 \mathrm{~mL}$ of the bacterial suspension per pot.

For inoculum production, each bacterial isolate was grown in a $125 \mathrm{~mL}$ Erlenmeyer flask containing $60 \mathrm{~mL}$ of nutrient broth (meat extract: $1.0 \mathrm{~g} \mathrm{/} \mathrm{L,} \mathrm{yeast} \mathrm{extract:} 2.0 \mathrm{~g} \mathrm{/} \mathrm{L}$, peptone: $5.0 \mathrm{~g} / \mathrm{L}, \mathrm{NaCl}: 5.0 \mathrm{~g} / \mathrm{L}, \mathrm{pH}: 6.8 \pm 0.2$ ) and cultures incubated in BOD at $28^{\circ} \mathrm{C}$ for 24 hours. Subsequently, samples were standardized by reading in spectrophotometer at $630 \mathrm{~nm}$ (Kloepper et al., 1989), adjusting cell concentration to $1.5 \times 10^{8}$ colony forming units per $\mathrm{mL}$ (CFU $\mathrm{mL}^{-1}$ ).

\section{Plant evaluation, Shoot and root dry mass}

Plants were properly collected from pots separating root from shoot and dried in oven under forced ventilation at $65^{\circ} \mathrm{C}$ for approximately 72 hours until constant mass. The mass of the dried plant material was measured in analytical scale to determine the shoot and root dry matter in grams.

\section{Bioinformatics analysis and BOX-PCR}

Isolates were obtained from the collection of microorganisms of the Laboratory of Soil Microbiology, Faculty of Agrarian and Veterinary Sciences, State University of São Paulo (UNESP), Jaboticabal, Brazil.

Bacillus subtilis isolates

All $B$. subtilis isolates used in this study were characterized by Lobo et al., 2019.

\section{BOX-PCR Repetitive sequence amplification}

Regions of chromosomal DNAs from isolates were amplified using the BOX-PCR 1 R oligonucleotide (5'-CTA CGG GAC GAC GCT GAC G-3 ') (MARTIN et al., 1992).

PCR conditions were $80 \mathrm{ng}$ template DNA, $10 \mathrm{mM}$ each dNTP, $2 \mathrm{mM} \mathrm{MgCl}$, $10 \mathrm{X}$ buffer, 5 pmoles $\mu^{-1}$ BOX-A $1 \mathrm{R} 1 \mathrm{U}$ primer of Taq DNA polymerase (Fermentas ${ }^{\circledR}$ ) and sterile milli-Q water to complete the final volume of $20 \mu \mathrm{L}$.

Amplification was performed in thermocycler according to the following program: 1 cycle at $95^{\circ} \mathrm{C}$ for $5 \mathrm{~min}$; followed by 30 cycles of denaturation at $94^{\circ} \mathrm{C}$ for $1 \mathrm{~min}$; pairing at 53 - $\mathrm{C}$ for $1 \mathrm{~min}$; and extension at $65^{\circ} \mathrm{C}$ for $8 \mathrm{~min}$; final extension at $65^{\circ} \mathrm{C}$ for $16 \mathrm{~min}$ and final cycle of $4^{\circ} \mathrm{C}$.

\section{Comparison of isolates by metabolic profile}

Isolates were compared by the ability to metabolize carbon sources in a BiologEcoPlate ${ }^{\text {TM }}$ kit (Garland; Mills, 1991). Each plate contains 31 of the carbon sources divided into five categories: carbohydrates, amine, polymer, carboxylic acid and amino acids. These 31 carbon sources have 3 replicas of each substrate, and control without carbon source. Substrate utilization is spectrophotometrically measured by means of reaction, where tetrazolium indicator dye changes the coloration of the medium to violet by the metabolic activity of cells.

Isolates were cultivated in nutrient broth (meat extract: 1.0 g / L, yeast extract: $2.0 \mathrm{~g} / \mathrm{L}$, peptone: $5.0 \mathrm{~g} / \mathrm{L}, \mathrm{NaCl}: 5.0 \mathrm{~g} /$ $\mathrm{L}, \mathrm{pH}: 6.8 \pm 0.2$ ) for two days, under stirring at $100 \mathrm{rpm}$ and $28^{\circ} \mathrm{C}$ to form the pre-inoculum; after this period, $25 \mathrm{~mL}$ of culture were centrifuged at $15^{\circ} \mathrm{C}$ for 20 minutes at 12000 $\mathrm{rpm}$. Precipitated cells were suspended in nutrient broth giving rise to a cell suspension with OD $\left({ }_{560}\right)$ of 0.1 . This suspension was then cultured for 3 hours under the same condition as above to form a cell suspension with OD $\left({ }_{560}\right)$ of 0.2. Then, $150 \mu \mathrm{L}$ of this bacterial suspension was distributed to each BiologEcoPlate ${ }^{\mathrm{TM}}$ microplate well under laminar flow, remaining at $27^{\circ} \mathrm{C}$ in a biological oxygen demand incubator (BOD incubator) for 5 days. Carbon source consumption was measured on a MultiScan Go plate spectrometer (ThermoScientific) at $590 \mathrm{~nm}$. Readings were immediately taken after the addition of the suspension of each isolate to the plate (TO) and every 24 hours for 5 consecutive days. Control readings (without substrate, only water) were subtracted from each substrate reading. Data generated allowed the comparison of the metabolic profile of each isolate in relation to the number of substrates used, average well color development after $120 \mathrm{~h}$ of incubation.

\section{Soil analysis}

All analyses were performed in quintuplicate. Microbial respiratory activity was determined in $2.5 \mathrm{~L}$ flasks with $100 \mathrm{~g}$ 
soil containing a beaker with $20 \mathrm{ml} 0.5 \mathrm{M}$ sodium hydroxide. After incubation for 5 days at $28^{\circ} \mathrm{C}$ in the dark, sodium hydroxide was titrated with $0.5 \mathrm{M}$ hydrochloric acid (Rezende et al., 2004; de Andrade Barbosa et al., 2019).

Microbial biomass carbon was measured according to irradiation methods (Ferreira et al., 1999). The irradiation time to which soil samples were submitted was determined according to Islam and Weil (1998). Carbon extraction was performed with $0.5 \mathrm{M}$ potassium sulfate, and the extract was oxidized with $0.066 \mathrm{M}$ potassium dichromate in acid medium. Quantitation was performed by titration with $0.33 \mathrm{M}$ ammonium ferrous sulfate.

Soil moisture was verified after drying each sample in oven at $100^{\circ} \mathrm{C}$ for 24 hours. Then, precision scale was used to compare the final weight and the initial weight. For soil moisture determination, Equation 1 was used.

$\mathrm{U}=\frac{M u-M s}{M s} .100$

$\mathrm{U}=\begin{gathered}\text { Ms } \\ \text { Where } \mathrm{U}\end{gathered}$

wet soil mass (g); Ms = dry soil mass (g).

\section{Enzyme activity - dehydrogenase}

Dehydrogenase activity was determined according to Casida et al. (1964).

\section{Statistical analysis}

Results of metabolic profile variables through substrate consumption are presented in the heatmap. To obtain information about the microbial metabolic profile, especially for presenting five absorbance reading times, mathematical calculation was performed for each substrate using the formula proposed by Hackett and Griffiths (1997), which suggests the use of an equation using data from all times, defining metabolism and substrate consumption throughout the incubation period. Then, data were submitted to normalization proposed by Weber et al. (2007). Subsequently, hierarchical grouping heatmaps were generated using the " $R$ " software (The $R$ Project for Statistical Computing, 2014) through the Ward's linking method and the Euclidean distance of consumption between carbon sources. All analyses were performed in quintuplicate and results were expressed using mean \pm standard deviation. One-way analysis of variance (ANOVA) was used, followed by Tukey's test at 5\% significant level. Principal component analysis (PCA) was used to describe the relationship between carbon source consumption and plant growth promotion according to each isolate used. PCA was performed using a correlation matrix based on Pearson correlation coefficients after data standardization to avoid the influence of different orders of magnitude or units on results. A PCA score chart was used for sample distribution and a correlation chart was used to record the importance and interactions of variables. To assess the correlation, the standard described by Teles et al. (2018) was used, in which $r$ values between -0.3 and 0.3 characterized negligible correlation; from 0.3 to 0.5 (or -0.3 to -0.5 ) low correlation; $r$ values from 0.5 to 0.7 (or -0.5 to -0.7 ) indicate moderate correlation; $r$ values from 0.7 to 0.9 (or -0.7 to -0.9 ) means strong correlation or high ratio and finally $r$ values between 0.9 and 1.0 (or -0.9 to - 1.0) implies very strong or high correlation (Mukaka, 2012). Statistical analyses were performed using the $\mathrm{R}$ language version software 3.2.4 ( $\mathrm{R}$ Foundation for Statistical Computing, Vienna, Australia) and the Fac-package to Mine R version 1.32, Factoextra package version 1.0.5 and the performance analysis package version 1.4.3541.

\section{Conclusion}

The analyses carried out did not allow a better understanding of the action of isolates in promoting plant growth, but it can be observed that the isolate with the highest ability to promote plant growth was the only isolate that consumed glycyl-L- glutamic. These results open the way for further investigations in an attempt to clarify what are the conditions and / or characteristics required in isolates for the plant growth promotion to be more effective.

\section{Acknowledgment}

The author thank CAPES for the scholarship Code 001.

References

Abdi H, Williams LJ (2010) Principal component analysis. Wiley interdisciplinary reviews: computational statistics 2(4):433-459.

Almagro M, López J, Querejeta J , Martínez-Mena M (2009) Temperature dependence of soil $\mathrm{CO} 2$ efflux is strongly modulated by seasonal patterns of moisture availability in a Mediterranean ecosystem. Soil Biol Bioch. 41(3):594605

Almaraz JJ, Zhou X, Mabood F, Madramootoo C, Rochette P, Ma B-L , Smith DL (2009) Greenhouse gas fluxes associated with soybean production under two tillage systems in southwestern Quebec. Soil Till Res. 104(1):134-139.

Aloo B, Makumba B, Mbega E (2019) The potential of bacilli rhizobacteria for sustainable crop production and environmental sustainability. Microbiol Res. 219:26-39.

Altschul SF, Madden TL, Schäffer AA, Zhang J, Zhang Z, Miller W, Lipman DJ (1997) Gapped BLAST and PSI-BLAST: a new generation of protein database search programs. Nucl Ac Res. 25(17):3389-3402.

Bhattacharyya PN, Jha DK (2012) Plant growth-promoting rhizobacteria (PGPR): emergence in agriculture. World J Microbiol Biotechnol. 28(4):1327-1350.

Bredemeier C, Mundstock CM (2000) Regulation of nitrogen absortion and assimilation in plants. Ciênc Rur. 30(2):365372.

Buchanan BB, Gruissem W, Jones RL (2015) Biochemistry and molecular biology of plants. John Wiley, Sons

Casida Jr L, Klein D , Santoro T (1964) Soil dehydrogenase activity. Soil Sci. 98(6):371-376.

Chavez LF, Amado TJC, Bayer C, La Scala NJ, Escobar LF, Fiorin JE, Campos B-HCd (2009) Carbon dioxide efflux in a Rhodic Hapludox as affected by tillage systems in southern Brazil. Rev Bras Ciênc Solo. 33(2):325-334.

Chowdhury SP, Dietel K, Rändler $M$, Schmid $M$, Junge $H$, Borriss R, Hartmann A, Grosch R (2013) Effects of Bacillus amyloliquefaciens FZB42 on lettuce growth and health under pathogen pressure and its impact on the rhizosphere bacterial community. Plos one. 8(7):e68818.

Compant S, Duffy B, Nowak J, Clément C, Barka EA (2005) Use of plant growth-promoting bacteria for biocontrol of plant diseases: principles, mechanisms of action, and future prospects. Appl Environ Microbiol. 71(9):4951-4959. 
de Andrade Barbosa M, de Sousa Ferraz RL, Coutinho ELM, Neto AMC, da Silva MS, Fernandes C, Rigobelo EC (2019) Multivariate analysis and modeling of soil quality indicators in long-term management systems. Sci Total Environ. 657:457-465

Diaz PAE, Baron NC, Rigobelo EC (2019) 'Bacillus' spp. as plant growth-promoting bacteria in cotton under greenhouse conditions. Austr J Crop Sci. 13(12):2003. Garland JL, Mills AL (1991) Classification and characterization of heterotrophic microbial communities on the basis of patterns of community-level sole-carbonsource utilization. Appl Environ Microbiol. 57(8):23512359.

Gill SS, Tuteja N (2010) Reactive oxygen species and antioxidant machinery in abiotic stress tolerance in crop plants. Plant Phys Bioch. 48(12):909-930.

Glick BR (2012) Plant growth-promoting bacteria: mechanisms and applications. Scient. 2012.

Gordon D, Abajian C, Green P (1998) Consed: a graphical tool for sequence finishing. Genome Res. 8(3):195-202.

Goswami D, Thakker JN, Dhandhukia PC (2016) Portraying mechanics of plant growth promoting rhizobacteria (PGPR): a review. Cogent Food Agr. 2(1):1127500.

Gu Y, Wang P, Kong C (2009) Urease, invertase, dehydrogenase and polyphenoloxidase activities in paddy soil influenced by allelopathic rice variety. Eur J Soil Biol. 45(5-6):436-441.

Gupta G, Parihar SS, Ahirwar NK, Snehi SK, Singh V (2015) Plant growth promoting rhizobacteria (PGPR): current and future prospects for development of sustainable agriculture. J Microb Biochem Technol. 7(2):096-102.

Hackett CA, Griffiths BS (1997) Statistical analysis of the time-course of Biolog substrate utilization. J Microbiol Method. 30(1):63-69

Hayat R, Ali S, Amara U, Khalid R, Ahmed I (2010) Soil beneficial bacteria and their role in plant growth promotion: a review. Ann Microbiol. 60(4):579-598.

Islam K, Weil R (1998) Microwave irradiation of soil for routine measurement of microbial biomass carbon. Biol Fert Soils. 27(4):408-416.

Jenkinson D, Ladd J (1981) Microbial Biomass in soil: measurement and turnover. Soil Biochemistry. v.415-471

Jha PN, Gupta G, Jha P, Mehrotra R (2013) Association of rhizospheric/endophytic bacteria with plants: a potential gateway to sustainable agriculture. Green J Agricultural Sci. 3(2):73-84.

Kloepper JW, Lifshitz R, Zablotowicz RM (1989) Free-living bacterial inocula for enhancing crop productivity. Trends Biotechnol. 7(2):39-44.

Kuan KB, Othman R, Rahim KA, Shamsuddin ZH (2016) Plant growth-promoting rhizobacteria inoculation to enhance vegetative growth, nitrogen fixation and nitrogen remobilisation of maize under greenhouse conditions. PloS one. 11(3):e0152478.

Lal R (2009) Challenges and opportunities in soil organic matter research. Eur J Soil Sci. 60(2):158-169.

Larkin MA, Blackshields G, Brown N, Chenna R, McGettigan PA, McWilliam H, Valentin F, Wallace IM, Wilm A, Lopez R (2007) Clustal $W$ and Clustal $X$ version 2.0. Bioinformatics. 23(21):2947-2948.

Lea PJ, Miflin BJ (2018) Nitrogen assimilation and its relevance to crop improvement. Ann Plant Rev online:1-40

Li S-X, Wang Z-H, Stewart B (2013) Responses of crop plants to ammonium and nitrate $\mathrm{N} \mathrm{Adv}$ in Agron. vol 118. Elsevier, p 205-397.
Linn DM, Doran JW (1984) Effect of water-filled pore space on carbon dioxide and nitrous oxide production in tilled and nontilled soils 1. Soil Sci Soc Am J. 48(6):1267-1272

Lobo LLB, dos Santos RM, Rigobelo EC (2019) Promotion of maize growth using endophytic bacteria under greenhouse and field conditions. Aust J Crop Sci. 13(12):2067

Marmur J (1961) A procedure for the isolation of deoxyribonucleic acid from micro-organisms. J Mol Biol. 3(2):208-IN1.

Martin B, Humbert O, Camara M, Guenzi E, Walker J, Mitchell $T$, Andrew $P$, Prudhomme $M$, Alloing $G$, Hakenbeck R (1992) A highly conserved repeated DNA element located in the chromosome of Streptococcus pneumoniae. Nucl Ac Res. 20(13):3479-3483.

Mehmood U, Inam-ul-Haq M, Saeed M, Altaf A, Azam F, Hayat S (2018) A brief review on plant growth promoting Rhizobacteria (PGPR): a key role in plant growth promotion. Plant Prot. 2(2):77-82.

Mukaka MM (2012) A guide to appropriate use of correlation coefficient in medical research. Malawi Med J. 24(3):69-71.

Nelson LM (2004) Plant growth promoting rhizobacteria (PGPR): prospects for new inoculants. Crop Managemn. 3(1):0-0.

Patel T, Minocheherhomji F (2018) Plant growth promoting Rhizobacteria: blessing to agriculture. Int J Pure App Biosci. 6:481-92.

Paustian K, Six J, Elliott E, Hunt H (2000) Management options for reducing $\mathrm{CO} 2$ emissions from agricultural soils. Biogeoch. 48(1):147-163.

RAIJ Bv (1996) Recomendações de adubação e calagem para o Estado de São Paulo. IAC Campinas.

Raza W, Yousaf S, Rajer FU (2016) Plant growth promoting activity of volatile organic compounds produced by biocontrol strains. Sci Lett. 4(1):40-43.

Rezende L, Assis L, Nahas E (2004) Carbon, nitrogen and phosphorus mineralization in two soils amended with distillery yeast. Biores Technol. 94(2):159-167.

Sala MM, Estrada M, Gasol JM (2006) Seasonal changes in the functional diversity of bacterioplankton in contrasting coastal environments of the NW Mediterranean. Aquatic Microbial Ecol. 44(1):1-9.

Salazar S, Sánchez L, Alvarez J, Valverde A, Galindo P, Igual J, Peix A, Santa-Regina I (2011) Correlation among soil enzyme activities under different forest system management practices. Ecol Engin. 37(8):1123-1131.

Silva-Olaya A, Cerri CEP, La Scala Jr N, Dias CTdS, Cerri CC (2013) Carbon dioxide emissions under different soil tillage systems in mechanically harvested sugarcane. Environ Res Lett. 8(1):015014.

Taiz L, Zeiger E (2006) Fisiologia vegetal, vol 10. Universitat Jaume I.

Tamura K, Stecher G, Peterson D, Filipski A, Kumar S (2013) Molecular evolutionary genetics analysis version 6.0 . Mol Biol Evol. 30(12):2725-2729.

Teles AS, Chávez DW, Oliveira RA, Bon EP, Terzi SC, Souza EF, Gottschalk LM, Tonon RV (2019) Use of grape pomace for the production of hydrolytic enzymes by solid-state fermentation and recovery of its bioactive compounds. Food Res Intern. 120:441-448.

Tercé-Laforgue T, Bedu M, Dargel-Grafin C, Dubois F, Gibon Y, Restivo FM, Hirel B (2013) Resolving the role of plant glutamate dehydrogenase: II. Physiological characterization of plants overexpressing the two enzyme 
subunits individually or simultaneously. Plant and Cell Physiol. 54(10):1635-1647.

Wang H, Wen K, Zhao X, Wang X, Li A, Hong H (2009) The inhibitory activity of endophytic Bacillus sp. strain CHM1 against plant pathogenic fungi and its plant growthpromoting effect. Crop Protec. 28(8):634-639.

Weber KP, Grove JA, Gehder M, Anderson WA, Legge RL (2007) Data transformations in the analysis of communitylevel substrate utilization data from microplates. J Microbiol Method. 69(3):461-469

Wei W, Jiang F, Oikawa T (2009) Contribution of root and microbial respiration to soil $\mathrm{CO} 2$ efflux and their environmental controls in a humid temperate grassland of Japan. Pedos. 19(1):31-39
Weisburg WG, Barns SM, Pelletier DA, Lane DJ (1991) 16S ribosomal DNA amplification for phylogenetic study. J Bacteriol. 173(2):697-703.

White Jr JF, Torres MS, Sullivan RF, Jabbour RE, Chen Q, Tadych M, Irizarry I, Bergen MS, Havkin-Frenkel D, Belanger FC (2014) Occurrence of Bacillus amyloliquefaciens as a systemic endophyte of vanilla orchids. Microsc Res Techn. 77(11):874-885.

Williams L, Miller A (2001) Transporters responsible for the uptake and partitioning of nitrogenous solutes. Ann Rev Plant Biol. 52(1):659-688.

Zhang X, Zhang R, Gao J, Wang X, Fan F, Ma X, Yin H, Zhang C, Feng K, Deng Y (2017) Thirty-one years of rice-rice-green manure rotations shape the rhizosphere microbial community and enrich beneficial bacteria. Soil Biol Biochem. 104:208-217. 